This is a postprint version of the following published document:

Vigil, M. R., Bravo, J., Baselga, J., Yamaki, S. B. \& Atvars, T. D. Z. (2003). Micromorphology and Relaxation Processes of Low Density Polyethylene Probed by Fluorescence Spectroscopys. Current Organic Chemistry, 7 (3), pp. 197-211.

DOI: $10.2174 / 1385272033373021$

(C) Bentham Science Publishers, 2003 


\title{
Micromorphology and Relaxation Processes of Low Density Polyethylene Probed by Fluorescence Spectroscopys
}

\author{
Maria R. Vigil ${ }^{\mathrm{a}}$, Julio Bravo ${ }^{\mathrm{b}}$, Juan Baselga*b ${ }^{\mathrm{b}}$, S.B. Yamaki ${ }^{\mathrm{c}}$ and Teresa D.Z. Atvars*c \\ ${ }^{a}$ Departamento de Organizacion Industrial, Escuela Superior de Ingeniería Industriales, Universidad Europea de \\ Madrid, c/Tajo s/n, 28670, Villaviciosa de Odón, Spain; \\ ${ }^{b}$ Departamento de Materiales, Escuela Superior de Ingeniería, Universidad Carlos III de Madrid, Leganés, Spain, \\ Departamento de Físico-Química, Instituto de Química, Universidade Estadual de Campinas, Caixa Postal 6154, 13083-970
} Campinas, SP, Brazil.

*Address correspondence to this author at the ${ }^{b}$ Departamento deMateriales, Escuela Superior de Ingeniería, Universidad Carlos III de Madrid, Leganés, Spain, Departamento de Físico-Quími ca, Instituto deQuímica, Universidade Estadualde Campinas, Cai xa Postal 61 54, 13083-970 Campinas, SP, Brazil; Tel: 55-19-37883 07 8; Fax: 55-19-37883023;E-mail:jbaselga@ing.uc3m.es, tatvars@iqm.un icamp.br.

\begin{abstract}
Fluorescence spectra of molecular guests at several temperatures are useful technique to study several types of polymer properties. In particular, it has been often employed to study polymer relaxation processes either in static or in dynamic conditions. In this work some applications of the steady-state fluorescence spectroscopy of different guests in polyethylene and in particular reports the photophysical behavior of 1,3-di(1-pyrenyl)propane (1Py(3)1Py) sorbed in low density polyethylene are shown. This molecular probe differs of pyrene by its ability to form intramolecular excimer species and we discuss the temperature dependence of this formation. In this study we recorded simultaneously the fluorescence spectra and the differential scanning calorimetry (dsc) traces. The relative dependence of fluorescence intensities on temperature of the higher energy vibronic band at $367 \mathrm{~nm}$, of the isolated choromophore emission and of the excimer emission were discussed and associated with the polyethylene polymer relaxation processes. The influence of the macroscopic stretching upon the polymer relaxation processes and the fluorescence emission was also investigated and compared with previous results.
\end{abstract}

\section{INTRODUCTION}

Polyethylenes form a family of semicrystalline polymers with a wide range of properties and applications [1,2]. As semicrystalline polymers, they are composed of several hierarchical structures including a crystalline phase, an amorphous portion and an interface between the crystalline and amorphous regions [3,4]. Several factors control the relative proportion of each of these domains, including the synthesis method, processing and in service conditions. Low density polyethylene (LDPE) is a sub-class of polyethylenes whose properties derive from branching of the macromolecular chains and from its molecular weight distribution. Usually, low density polyethylenes are also semicrystalline polymers exhibiting a melting temperature around $110-120^{\circ} \mathrm{C}$ and a crystallinity degree of ca. $30-50 \%$ [2].

The use of polyethylenes as useful host matrices for spectroscopic guests renders correct assignments for electronic and vibrational transitions because of the facility of orientation of the polymer, which induces an average alignment of the guests parallel to the drawing direction $[5,6]$. The efficiency of the partial alignment of the molecular guests depends on the method of their incorporation into the polymer host [7].
Studies of microscopic morphological modifications of stretched polyethylene were also the subject of different approaches. Among them, the relative efficiency of photoproducts of molecules dissolved in stretched polyethylenes, compared to unstretched matrices, was reported and the differences were attributed to a decrease in the available free volume of the matrices $[8,9]$. Some additional evidence that the macroscopic stretching of polyethylene films produced a decrease of the free volume resulted from studies using positron annihilation measurement and fluorescence spectroscopy [9-11].

Additional focuses were introduced in studies of the temperature dependence of the luminescence properties of fluorescent condensed aromatic hydrocarbons, because they allowed the determination of the polymer relaxation processes [10-22]. Luminescent polymers necessary for these studies may be produced by several methods: copolymerization of luminescent monomers, sorption of luminescent guests in a polymer host and chemical modification of pre-formed polymer attaching luminescent groups [11,12,16-20,23-25]. These and many other studies assumed that the molecular fluorescent probes sorbed or attached to the polymer chain in semicrystalline polymers were distributed among the amorphous and interfacial crystalline-amorphous portions of the material and, consequently, these were the domains that could be probed $[5,6,10,11]$.

The temperature dependence of the luminescence of several guests or labels in polymers is a complex process and different approaches have been employed [10-22]. It was demonstrated that phosphorescence emission of several probes sorbed in different polymers were able to detect the 
polymer relaxation processes [29]. Arrhenius plot of the phosphorescence intensities versus reciprocal of the temperature showed slope changes associated with the polymer relaxation with apparent activation energies characteristic of the relaxation processes. Other studies using phosphorescent molecules of different sizes and shapes demonstrated that smaller molecules detect relaxation processes involving shorter segments of the polymer chain [21]. We also showed that Arrhenius plot is a good representation for some temperature ranges although it can not be employed for the entire range [10,11,13,21]. Further works reported that different functions for the temperature dependence of the luminescence emission or for luminescence decay rates should be employed for different temperature ranges. Attempts to apply the Williams-LandelFerry (WLF) approach in studies of polymer relaxation processes above the glass transition temperature, according to the free-volume theory, was postulated for intrinsically fluorescent polymers [16-20,30]. These results showed that the intramolecular conformation changes of the probes resulting in excimer emission were controlled by the glass transition of the matrix. However, the mobility processes of the segments are not exactly equivalent to those determined by viscoelastic measurements $[16,18]$. The microscopic dynamics of polymer systems using fluorescent guests were also studied using three different analytical functions for different temperature ranges of the temperature dependence of the fluorescence rate constants [22]. According to the mode-coupling theory, there is a critical temperature, $T_{\mathrm{c}}$, above which the nonradiative decay time follow a power-law equation. Between this temperature and the glass transition, $\mathrm{T}_{\mathrm{g}}$, the decay should be fitted by a Vogel-Tammann-Fulcher law and below $T_{\mathrm{g}}$ an Arrhenius-type function represents the experimental results [22]. Thus, although the Arrhenius-type function is not ideal to represent the dependence of the fluorescence intensities on the entire temperature range, the slope changes observed in the plot are related to the polymer relaxation processes determined by other techniques. In conclusion, we should assume that there is not a unique kinetic model to describe the temperature dependence of the luminescence emission of guests or attached groups in polymer systems that could be employed for the entire temperature range. Nevertheless, luminescence emission is a useful technique in studies of polymer relaxation processes and the temperature that of the process is very similar to that determined by other techniques (MDTA, dielectric relaxation, NMR, etc.).

Polyethylene undergoes several types of relaxation processes whose assignments are still controversial [31-56]. In general, it has been accepted that polyethylene relaxation processes are named using greek letters in order of the increase of the temperature: $T_{\gamma}=150-200 \mathrm{~K}, \mathrm{~T}_{\beta}=200-270 \mathrm{~K}$ and $\mathrm{T}_{\alpha}=275-350 \mathrm{~K}$. The higher temperature relaxation processes precedes the melting temperature of the crystalline phase, which ranges between $373 \mathrm{~K}$ to $413 \mathrm{~K}$, depending on the polymer crystallinity. In previous reports using benzophenone as a phosphorescent guest in low and high density polyethylenes, the $\gamma$-relaxation process at $140-150 \mathrm{~K}$ [13], was observed in agreement with other techniques. Furthermore, using anthracene sorbed in the same matrices or anthryl groups attached to the polymer chain, this relaxation was observed at the same temperatures. In addition, these results showed that the $\beta$-relaxation occurs at $230-240 \mathrm{~K}$ while the $\alpha$-relaxation occurs at $340 \mathrm{~K}[10,11]$.

When pyrene was sorbed in LDPE [14], the influence of the $\alpha$ - and $\beta$-relaxation processes for LDPE on the fluorescence intensity of the probe was also postulated and the temperature for both polymer relaxation processes was determined from steady-state fluorescence measurements. In the case of pyrene it was postulated that the molecular probe was located at the interface between the amorphous and crystalline phases. Fluorescence spectra showed a low intensity emission band at higher energy than the 0-0 band. This side band was linked to the $0-0$ band in such a way that its intensity increased with temperature (within a certain temperature range) at the expense of the 0-0 emission.

Simple electron-phonon coupling concepts, based in the interaction between an optically active center and a number of phonons in a dynamic lattice (the partially ordered cavity) helped to understand this upward behavior: vibrational modes of the matrix distort the pyrene environment introducing an oscillating field that changes the electronic energy of pyrene $[14,15]$. According to this model we calculated the energy of these phonons that was coincident with some of the polyethylene $\mathrm{CH}$ vibrations normal modes, more specifically with the $2810 \pm 35 \mathrm{~cm}^{-1}$ and $1437 \pm 61 \mathrm{~cm}^{-1}$ modes. Thus, what we demonstrated previously was that although pyrene is dissolved into the polymer matrix and that the host-guest interaction is weak (van der Walls forces) there is a electron-phonon coupling where the matrix acts as a sink for the excess of vibrational energy of the guest. We also demonstrated that this coupling depends on the temperature and is affected by the movements of the polymer chains. However, some queries arose from that work: i) is the size and shape of the host cavity influencing the photophysical properties of the fluorescent guests? ii) What is the relation between polymer relaxation processes and changes in the free-volume available for the fluorescent guest?

The present work shows an extension of the previous study, this time employing 1,3-di-(1-pyrenyl) propane, $1 \mathrm{Py}(3) 1 \mathrm{Py}$, as a fluorescent molecular guest sorbed in LDPE $[14,15]$. This probe was chosen as a convenient nanomorphological probe of the polymer matrix since: i) the pyrenyl moiety is a highly fluorescent group; ii) This group is able to form intramolecular excimers involving a very specific conformation of the pyrenyl moieties; and iii) the efficiency of excimer formation depends on the shape, size and mobility of the cavity where the guest is located and, consequently, the intramolecular excimer-forming molecules are convenient probes to evaluate all of these geometrical hindrances [26]. In addition, since the dynamic processes involving the intramolecular excimer-forming guest in several elastomeric polymers are dependent on the temperature, the probability of excimer formation is linked to the volume needed for intramolecular rearrangement of the probe [16-20]. Indeed, changes of the free-volume of the polymer matrix were related to the polymer relaxation processes and, thus, the interconnectivity among the freevolume and intramolecular conformational rearrangement of the guest will be also discussed. 
The dynamics of intramolecular excimer formation of di(1-pyrenyl) alkanes was studied in several fluid media $[27,28]$. The proposed mechanisms involve specific geometry or a distribution of conformations for excimer formation in solutions. Whatever is the best description for the dynamics of the $1 \mathrm{Py}(3) 1 \mathrm{Py}$ intramolecular excimers in fluid solutions that is considered, there is some evidence pointing out that the mechanism and the temperature dependence of its formation should be much more complex in a solid state polymer matrix because of: i) the efficiency of the excimer emission was always lower for probes in polymer matrices, compared to fluid solutions $[16,20]$; ii) the polymer matrix imposes steric hindrances to the guest molecules and a different proportion of each conformer structure should be achieved; iii) a large fraction of excimer conformers, but not all, arise from a dynamic mechanism that is partially inhibited in rigid matrices [26]. Although for some purposes the use of excimer-forming probes may be inconvenient because the mechanism is not precisely defined, these are very convenient probes for studies of freevolume in polymer systems since this property controls the efficiency of the excimer formation.

To address some of these tasks, the temperature dependence of the $1 \mathrm{Py}(3) 1 \mathrm{Py}$ monomer and excimer fluorescence under steady-state excitation conditions were studied. The role of the polymer relaxation processes and the influence of the macroscopic stretching of the polymer matrix were also analyzed. Since the experimental temperature range is $170-420 \mathrm{~K}$, the study is limited to the $\alpha$-and $\beta$-relaxation processes.

\section{EXPERIMENTAL SECTION}

1,3-Di-(1-pyrenyl) propane, $1 \mathrm{Py}(3) 1 \mathrm{Py}$, was purchased from Molecular Probes and was used as received. Commercial LDPE was molded as described elsewhere [14]. Slices of about $20 \mathrm{~mm} \times 80 \mathrm{~mm} \times 0.4 \mathrm{~mm}$ (thick) were immersed in chloroform and then vacuum dried at $50^{\circ} \mathrm{C}$ for $3 \mathrm{~h}$ following the protocol established earlier [14]. The cleaned and dried slices were immersed in a $10^{-4} \mathrm{~mol} \mathrm{~L}^{-1}$ solution of $n$-heptane/1Py(3)1Py for a period of 2 hours. Then, the sample surface was washed with $n$-heptane to remove any residual $1 \mathrm{Py}(3) 1 \mathrm{Py}$ from the surface. Finally, the solvent was removed by extensive vacuum drying $\left(10^{-2}\right.$ $\mathrm{mmHg}$ ) for a week. The concentration of $1 \mathrm{Py}(3) 1 \mathrm{Py}$ in the polymer matrix was estimated by UV spectrometry as $10^{-5}$ mol L-1.

Oriented LDPE slices were stretched to $300 \%$ at room temperature using a Universal Microtest DT7005/M machine. The sliding rate was selected as $1 \mathrm{~mm} / \mathrm{min}$. It should be emphasized that the previous thermal history is absolutely the same for stretched and unstretched samples and, thus, the only difference between them is the macroscopic stretching.

The data for the fluorescence intensity was taking after correction of the base line for each spectrum, since this line fluctuates during the measurements. For this correction we considered the initial value at $350 \mathrm{~nm}$ and the end point at
$500 \mathrm{~nm}$. For both of these points the light scattering was minimum.

Calorimetric (Perkin-Elmer 7 differential scanning calorimeter) and fluorimetric (Perkin-Elmer LS-50B spectrofluorimeter) measurements were simultaneously performed using a home-made optical arrangement for coupling both instruments [57], following the protocol defined previously $[14,15]$. Simultaneous here means that the sample was located in an aluminum pan inside the calorimeter, covered with a quartz window and excited by the light source from the fluorimeter using a bifurcated optical cable. The fluorescence emission was collected with the same optical fiber and transferred to the detector of the fluorimeter. Thus, emission was collected at the same time as the dsc run. The dsc traces are virtually the same for stretched and non-stretched samples and are very similar to those reported previously $[14,15]$. The excitation wavelength was selected as $337 \mathrm{~nm}$; the bandwidth slits for excitation and emission were 5 and $3 \mathrm{~nm}$, respectively; the emission spectra were recorded from $350 \mathrm{~nm}$ to $500 \mathrm{~nm}$, and the scan rate was selected to record each spectrum every $5.5 \mathrm{~K}$. Calorimetric measurements were performed at $2{ }^{\circ} \mathrm{C} / \mathrm{min}$ in the temperature range $170 \mathrm{~K}$ to $420 \mathrm{~K}$. The sample is inserted into the calorimeter at room temperature; cooled down to $170 \mathrm{~K}$ and allowed to thermalize for $30 \mathrm{~min}$ under a $\mathrm{N}_{2}$ atmosphere. Then, the sample was heated at the same rate and the fluorescence spectra were successively recorded (first heating cycle). When the temperature reached $420 \mathrm{~K}$, the sample was cooled down at the same rate and the fluorescence spectra were again successively recorded (cooling cycle). For stretched samples a second set of fluorescence spectra were recorded from 170 to $420 \mathrm{~K}$ (second heating cycle).

\section{RESULTS AND DISCUSSION}

\subsection{Fluorescence Spectra: General Assignments}

The fluorescence spectra were recorded for both the unstretched and the stretched $1 \mathrm{Py}(3) 1 \mathrm{Py} / \mathrm{LDPE}$ samples, simultaneously to the dsc trace recording. A set of fluorescence spectra were recorded for the unstretched $1 \mathrm{Py}(3) 1 \mathrm{Py} / \mathrm{LDPE}$ sample during the heating (173-423 K) and cooling (423-173 K) cycles and for the stretched sample during an additional second heating (173-423 K) cycle to erase the previous history of the sample. DSC traces showed only the endothermic peak due to the melting processes, independently of the sample stretching and occurred at 378 $\mathrm{K}$. Since the spectral profiles for 1Py(3)1Py sorbed in both unstretched and stretched LDPE matrices were similar and independent of the heating or cooling cycles, only the set of spectra for the heating cycle is shown in Fig. (1). Furthermore, the dsc trace is exactly the same as previously reported $[14,15]$, the figure was omitted. The only important information from this trace is the presence of the melting endothermic peak that occurs at $383 \mathrm{~K}$, independently of the stretching.

The fluorescence spectrum of $1 \mathrm{Py}(3) 1 \mathrm{Py}$ presents a set of vibronic bands ranging from $365 \mathrm{~nm}$ to $440 \mathrm{~nm}$, and a broad band centered at ca. $483 \mathrm{~nm}$ that starts at ca. $440 \mathrm{~nm}$ and 
extends beyond the measured range. The relative intensity of these two envelops of bands depends on the temperature. As usually observed for alkyl derivatives of aromatic molecules, the fluorescence spectrum is shifted to lower energies, compared with pyrene emission and, thus, the first set of vibrational bands was attributed to the isolated monosubstituted alkyl pyrenyl moieties [24,26]. In addition, the structureless broad band centered at $\lambda_{\text {em }} \sim 480 \mathrm{~nm}$ was assigned to the excimer emission of the pyrenyl moieties $[26,27,28,58]$.

Compared with pyrene [14], the fluorescence spectrum of the $1 \mathrm{Py}(3) 1 \mathrm{Py}$ presents differences in the relative intensities of the vibronic bands, reflecting changes of the vibrational coupling with the electronic excited state. The vibronic bands were also broader due to the lower molecular symmetry that results in a more complex overlap among the several normal modes.

The increase of temperature induces a decrease of the entire spectral envelope of the $1 \mathrm{Py}(3) 1 \mathrm{Py}$ fluorescence spectra, for both unstretched and stretched LDPE matrices. The spectral profile and the temperature dependence were similar and could be explained by the increase of the efficiency of the radiationless processes of the isolated excited pyrenyl moieties [58]. Two isoemissive points were detected in both the heating and the cooling cycles of the samples; one appeared at $\lambda_{\mathrm{em}} \sim 370 \mathrm{~nm}$ and the other at $\lambda_{\mathrm{em}} \sim$ $440 \mathrm{~nm}$. The first one connects the band envelope centered at $390 \mathrm{~nm}$ (monomer envelope) with the low intensity and higher energy band centered at $\lambda_{\mathrm{em}} \sim 367 \mathrm{~nm}$; the second one connects the monomer band envelope with the low energy
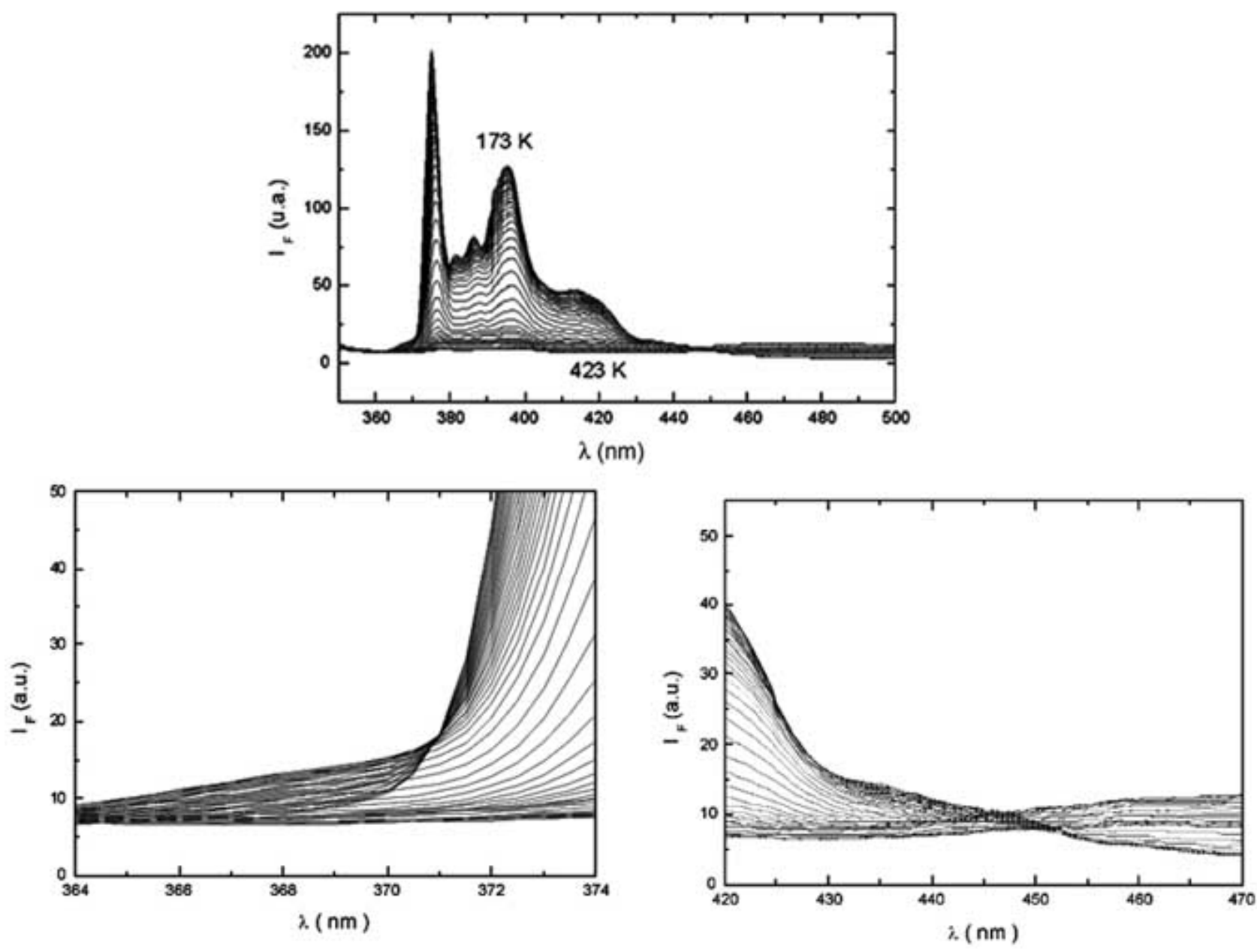

Fig. (1). Fluorescence spectra for the heating cycle of an unstretched 1Py(3)1Py/LDPE sample at several temperatures. Heating rate of 2 $\mathrm{K} / \mathrm{min}$. Inserts expand the wavelength region at the isoemissive points $\lambda_{\mathrm{em}}=367 \mathrm{~nm}$ and $\lambda_{\mathrm{em}}=483 \mathrm{~nm}$. 
band centered at $\lambda_{\mathrm{em}} \sim 483 \mathrm{~nm}$ (excimer envelope). The higher energy isoemissive point was previously observed for pyrene sorbed in LDPE $[14,15]$. Neither the excimer emission band nor the respective excimer/monomer isoemissive point were detected for pyrene guest dissolved in LDPE with a similar concentration of pyrenyl moieties and, thus, we assigned this structureless band to the intramolecular excimer emission of the $1 \mathrm{Py}(3) 1 \mathrm{Py}$ guestt,15].

For pyrene, the assignment of the band at $\lambda_{\mathrm{em}} \sim 365 \mathrm{~nm}$ was the subject of some discussion and Michl and Thulstrup attributed it to the origin of the ${ }^{1} L_{b}$ state [5]. They emphasized that the $A \rightarrow{ }^{1} L_{b}$ transition is strongly forbidden by symmetry rules and that its weakness is produced by Herzberg-Teller coupling involving the $a_{\mathrm{g}}$ in-plane symmetry vibrational modes, facilitated by the proximity between the ${ }^{1} \mathrm{~L}_{\mathrm{a}}$ and ${ }^{1} \mathrm{~L}_{\mathrm{b}}$ electronic excited levels, In addition, it was emphasized that the cooperative interaction with the immediate environment where the solute is located should modify the solute symmetry, relaxing the restrictions imposed by the symmetry rules. This higher energy band has also been observed in several homogeneous and micro-heterogeneous media independent of their polarity and viscosity. Regardless of the correct assignment of this band, it seems to be characteristic of the pyrenyl moiety since it is present in the fluorescence spectra of either pyrene or $1 \mathrm{Py}(3) 1 \mathrm{Py}$ molecules and its intensity seems to be also dependent on the temperature since it is undetectable at $30 \mathrm{~K}[10,11]$. In this and previous works $[14,15]$ we assume that this band results from the electron-phonon coupling between the guest and the host, and the temperature dependence should be well represented by this model.

\subsection{Temperature Dependence of the Fluorescence Spectra: Emission at $367 \mathrm{~nm}$}

The fluorescence spectra for stretched and unstretched $1 \mathrm{Py}(3) 1 \mathrm{Py} / \mathrm{LDPE}$ samples were recorded every $5.5 \mathrm{~K}$ and the temperature dependence of the intensities of the entire envelope centered at $390 \mathrm{~nm}$ and of the wavelengths at 367 $\mathrm{nm}$ and $483 \mathrm{~nm}$ was analyzed for both the heating and cooling cycles of the samples.

It is noteworthy that the temperature dependence of the bands at $367 \mathrm{~nm}$ and $483 \mathrm{~nm}$ followed inverse tendency with the changes of the temperature although both were undetectable at very low temperatures (Fig. (2)). The intensity of the band at $367 \mathrm{~nm}$ increased with the temperature and reached maximum values at $T \cong 280 \mathrm{~K}$ for unstretched and $\mathrm{T} \cong 300-310 \mathrm{~K}$ for stretched samples. Nevertheless, several other processes should competitively occur, whose efficiencies depend on the temperature: i) excimer emission remains undetectable at $T \leq 280 \mathrm{~K}$, ii) the relative intensity of the excimer band at $483 \mathrm{~nm}$ increased simultaneously with a decrease of the band intensity at 367 $\mathrm{nm}$ for $\mathrm{T}>280 \mathrm{~K}$ (unstretched) and $\mathrm{T}>310 \mathrm{~K}$ (stretched); and, finally, iii) the intensity at $367 \mathrm{~nm}$ achieved a minimum at a temperature coincident with the maximum excimer emission, ca $\approx 360 \mathrm{~K}$ (unstretched) and $\approx 370 \mathrm{~K}$ (stretched) (Fig. (2)). In addition, the temperature dependence of the

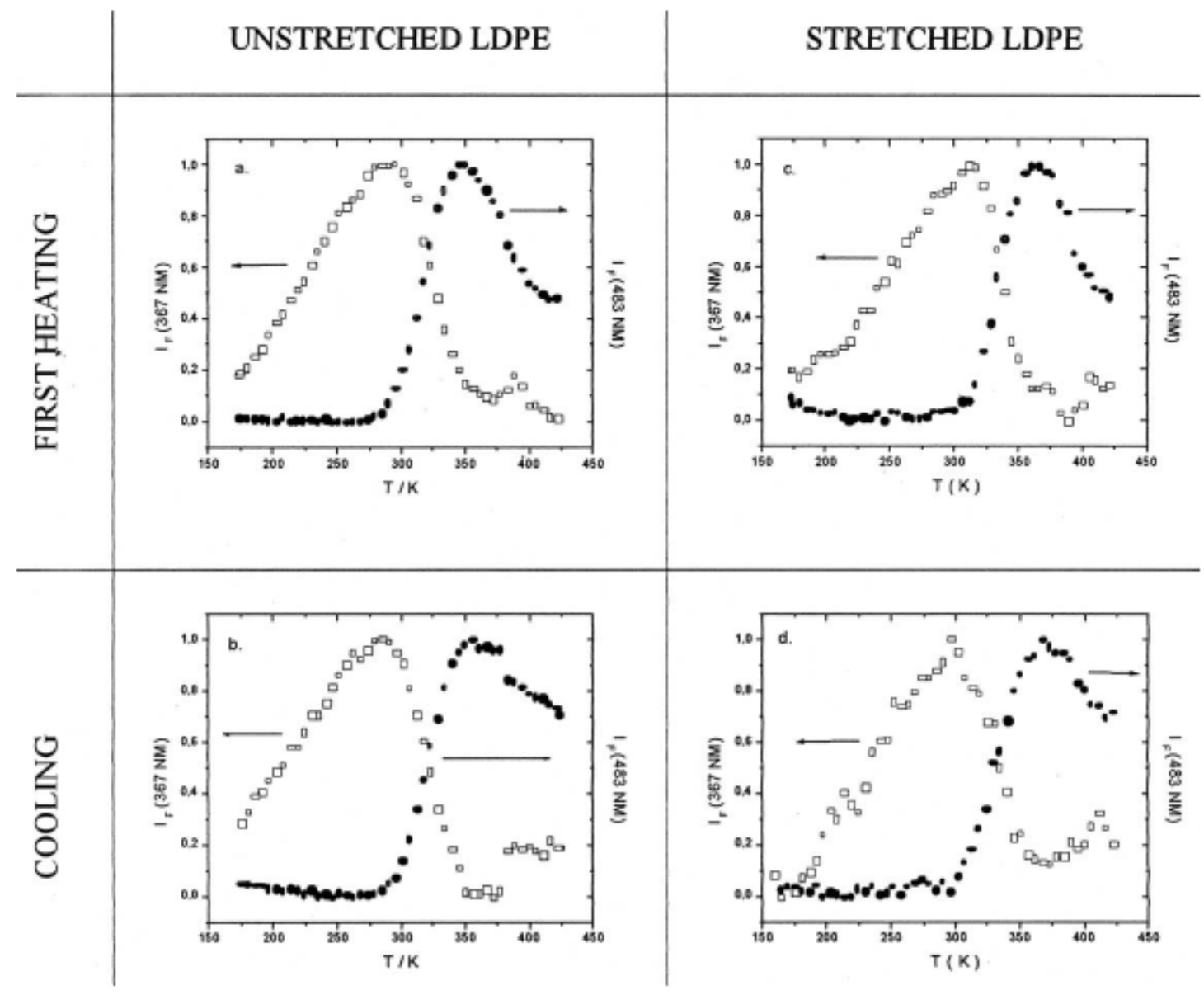



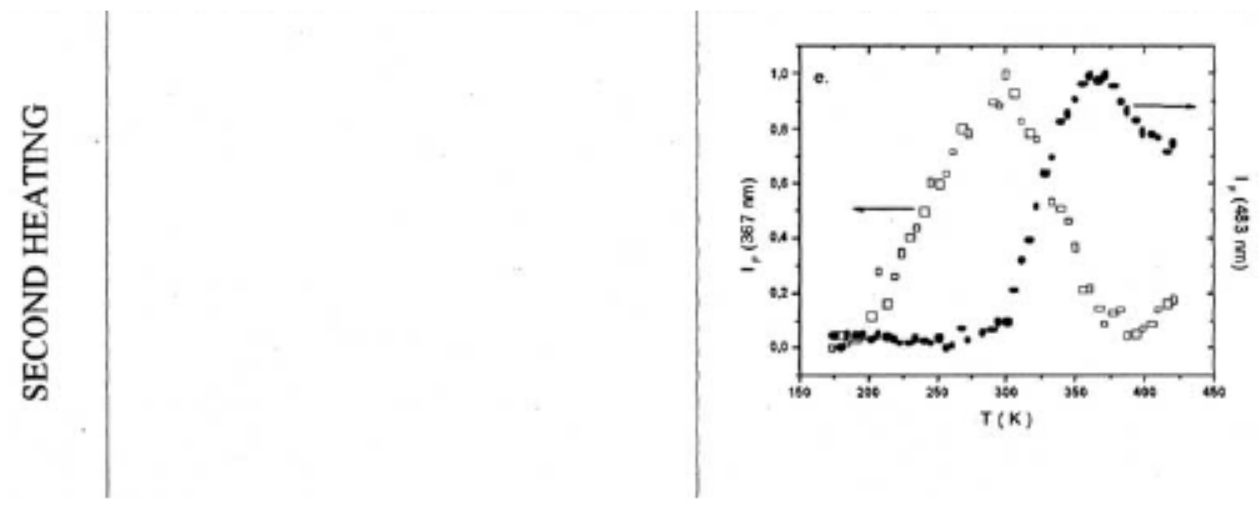

Fig. (2). Normalized fluorescence intensities, $\left(I_{0}\right)$, at $\lambda_{\mathrm{em}}=367 \mathrm{~nm}$ and $383 \mathrm{~nm}$, for 1Py(3)1Py/LDPE: in unstretched (a. heating and b. cooling cycles) and stretched (c. first heating, d. cooling and e. second heating cycles) at several temperatures. $I_{0}$ corresponds to the maximum intensity.

entire envelope centered at $390 \mathrm{~nm}$ follows the expected trend, decreasing the fluorescence intensity as the temperature increased (Fig. (3)). This result will be discussed further.

The temperature dependence of the $1 \mathrm{Py}(3) 1 \mathrm{Py}$ vibronic intensity at $\lambda_{\mathrm{en}} \approx 367 \mathrm{~nm}$ and the presence of the isoemissive point at $370 \mathrm{~nm}$ involving this and the $390 \mathrm{~nm}$ band envelope, in the absence of excimer emission, is very similar to the pyrene spectra in the same polymer. Thus, these data revealed that there exists a thermal equilibrium involving vibrational couplings originating from the $a_{g}$ and $b_{3 g}$ vibrational normal modes, respectively. Since a very small disturbance of the pyrenyl normal modes by the aliphatic

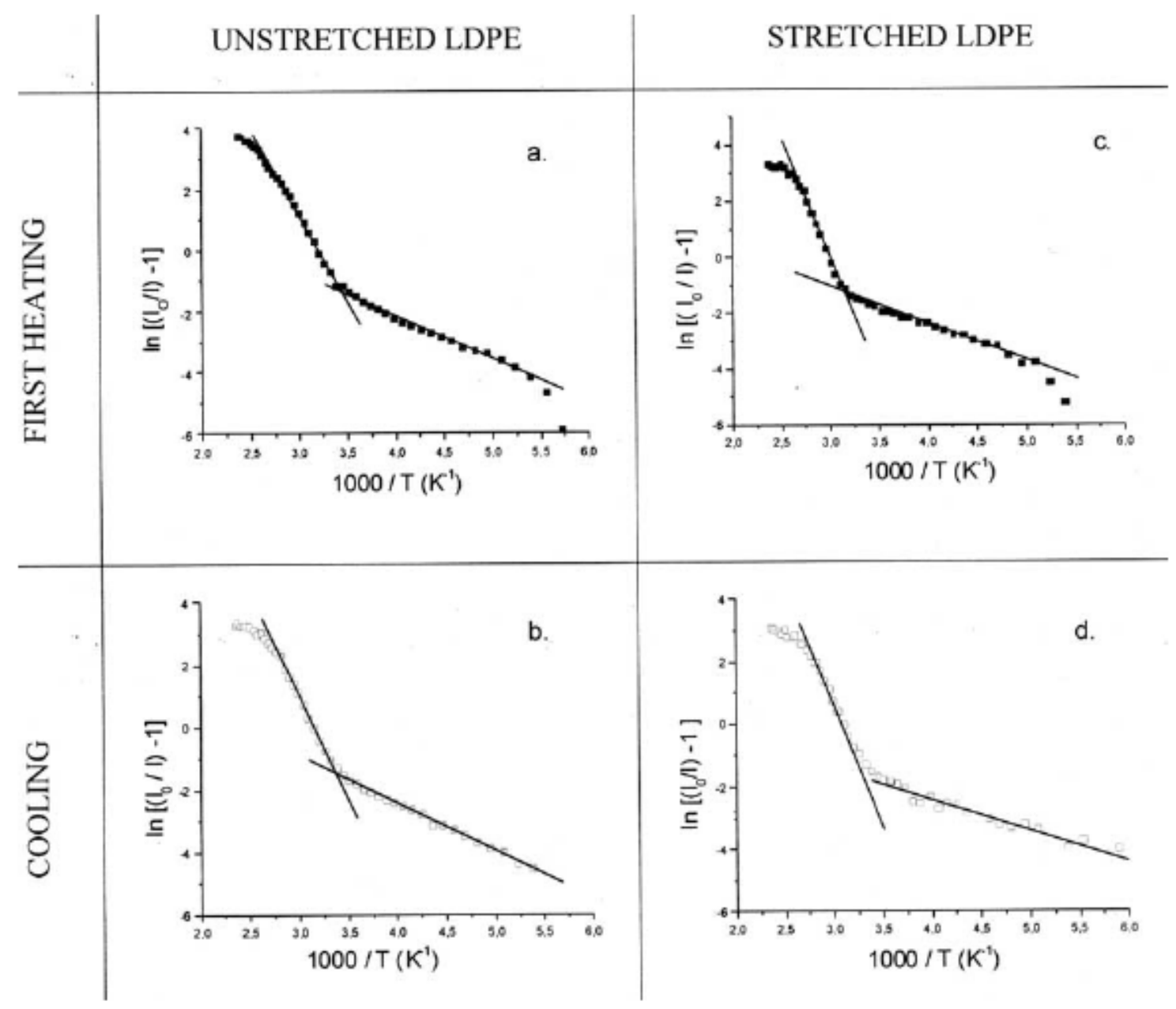



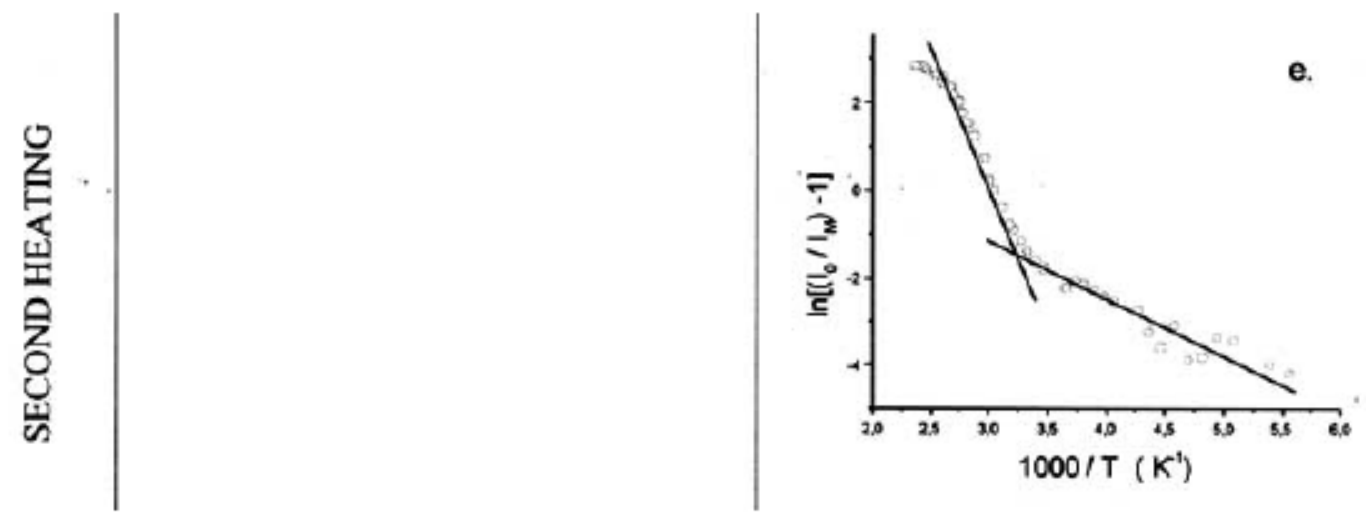

Fig. (3). Arrhenius plot, $I / I_{0}$ versus $1 / \mathrm{T}$, of the envelope at $390 \mathrm{~nm}$ and for $1 \mathrm{Py}(3) 1 \mathrm{Py} / \mathrm{LDPE}$ : in unstretched (a. heating and b. cooling cycles) and stretched (c. first heating, d. cooling and e. second heating cycles) at several temperatures. $\mathrm{I}_{0}$ corresponds to the integrated intensity at the lower temperature.

chain is expected, the occurrence of this coupling, either for pyrene or for the pyrenyl group of the $1 \mathrm{Py}(3) 1 \mathrm{Py}$, is not surprising.

In previous works the temperature dependence of pyrene fluorescence was successfully simulated by the BoseEinstein statistics (equation 1) [14,15]:

$$
\begin{gathered}
<n_{k}>=\frac{1}{\left[\exp \left(\frac{h \varpi(2 \pi)^{-1}}{k T}\right)-1\right]} \\
I_{F}\left(\lambda_{\text {em }}=367 \mathrm{~mm}\right) \alpha<n_{k}>
\end{gathered}
$$

where: $I_{F}$ is the fluorescence intensity at $\lambda_{e m}=367 \mathrm{~nm} ; n_{\mathrm{k}}$ is the number of phonons in mode $\mathrm{k}$ that are able to populate this state; $h$ is the Planck constant; $k$ is the Boltzmann constant; $T$ is the absolute temperature $(\mathrm{K})$; and $w\left(\mathrm{~cm}^{-1}\right)$ is the vibrational wavenumber of the phonon mode that produces the population of the $i$ state to be coupled to produce the emission at $367 \mathrm{~nm}$. Thus, we propose that the temperature dependence of the emission of this high-energy vibronic band originates from the electron-phonon coupling with its intensity proportional to the population of this state, $<n_{k}>[14,15]$.

The simulation of the electron-phonon coupling model was performed using the experimental data for the temperature dependence of the fluorescence intensity at 367 $\mathrm{nm}$ obtained for both unstretched and stretched $1 \mathrm{Py}(3) 1 \mathrm{Py} / \mathrm{LDPE}$ systems, during the heating and cooling cycles. Reasonable fits were obtained for temperatures up to 250-300 K (Fig. (4)). Nevertheless, some differences were observed from the profiles for the simulated curves for $1 \mathrm{Py}(3) 1 \mathrm{Py}$ and pyrene dissolved in the same type of LDPE $[14,15]$ : i) For pyrene doped samples the best fit of the BoseEinstein equation was obtained with two coupling wavenumbers, one for the temperature range $170-280 \mathrm{~K}$ and the other for $280-350 \mathrm{~K}$; ii) The maximum intensity for

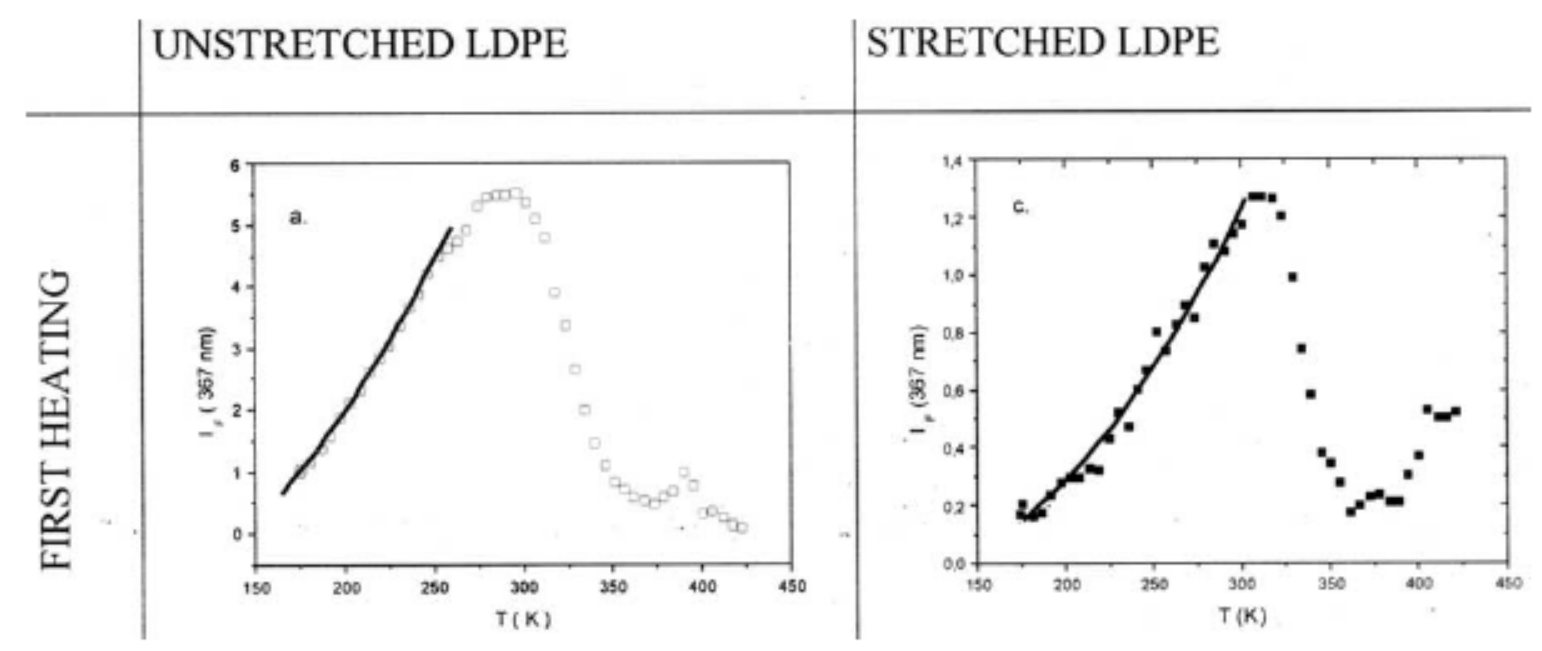




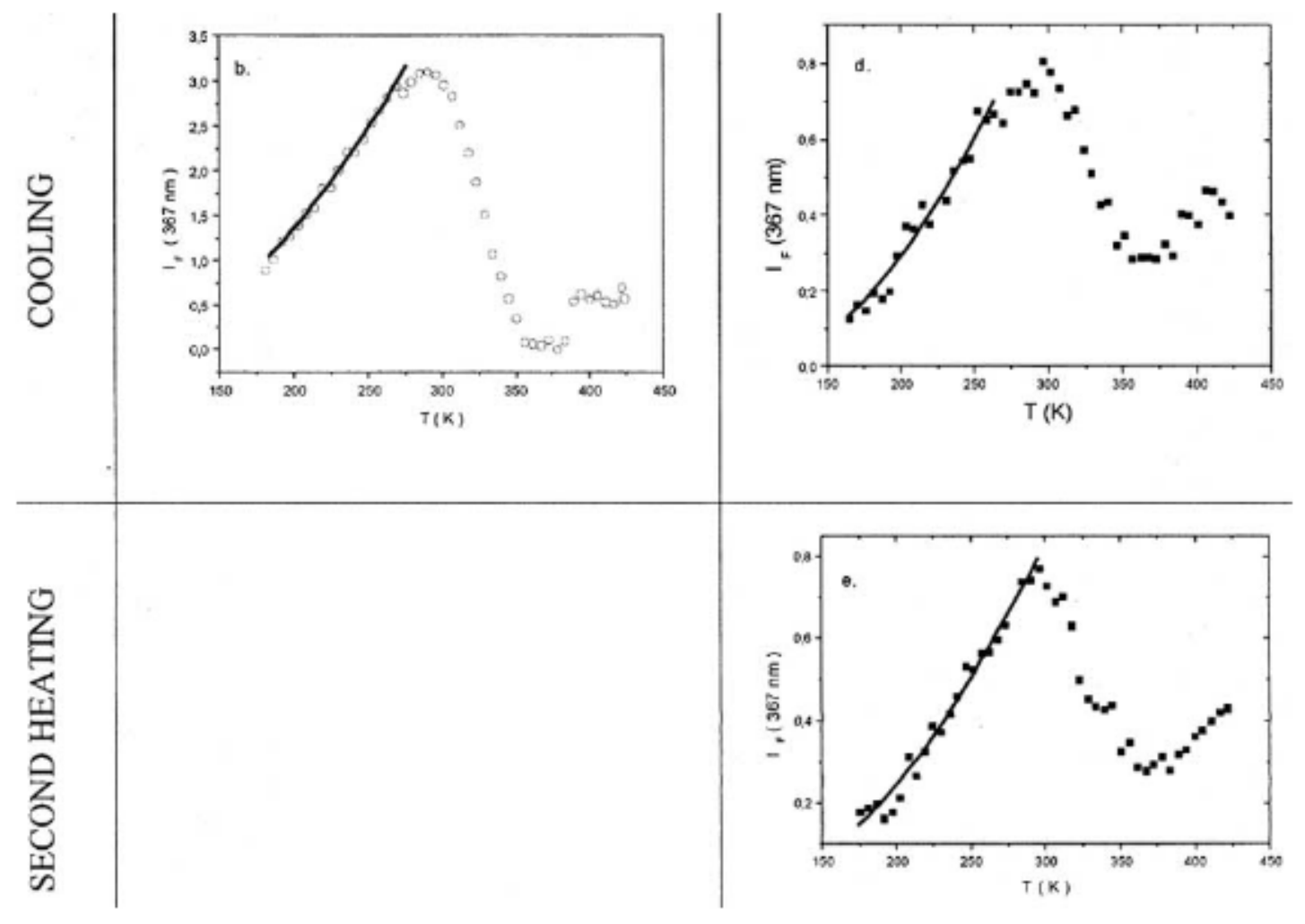

Fig. (4). Temperature dependence of the fluorescence intensity of the band at $367 \mathrm{~nm}, I_{F}(367 \mathrm{~nm})$. The lines represent the best fit for the Bose-Einstein function (equation 1) in the temperature ranges $173-280 \mathrm{~K}$. For wavenumber values see Table 1.

1Py(3)1Py doped samples was observed at $\mathrm{T} \approx 280 \mathrm{~K}$ (unstretched) (Fig. (4a,b)) and $\mathrm{T} \approx 310 \mathrm{~K}$ (stretched) (Fig. (4c-e)), and an acceptable fitting was simulated including only one wavenumber, iii) The coupling wavenumbers calculated for either pyrene or $1 \mathrm{Py}(3) 1 \mathrm{Py}$ in the unstretched matrix were virtually the same, ca. $\varpi \approx 2810 \pm 35 \mathrm{~cm}^{-1}$ and $\sigma$ $\approx 2795 \pm 61 \mathrm{~cm}^{-1}$, respectively, for the same temperature range, ca. 170-280 $\mathrm{K}$; iv) The maximum intensity was observed at a higher temperature for pyrene $(T \approx 350 \mathrm{~K})$ than for $1 \mathrm{Py}(3) 1 \mathrm{Py}(\mathrm{T} \approx 300 \mathrm{~K})$, reflecting a stronger coupling between the probe and the matrix in the pyrene/LDPE system.
The transition temperatures determined applying the electron-phonon coupling model for the fluorescence intensity at $367 \mathrm{~nm}$ of $1 \mathrm{Py}(3) 1 \mathrm{Py} / \mathrm{LDPE}$ for both the unstretched (non-oriented probe/matrix) and stretched (oriented probe/matrix) samples were virtually the same (Fig.(3)). Nevertheless, higher wavenumbers were calculated from the first heating cycle of the stretched sample than for the equivalent cycle of the unstretched one. After melting and subsequent cooling, the calculated wavenumbers were again very similar for both the unstretched and stretched samples, reflecting that the previous orientation was completely relaxed and the sample history was erased (Table 1).

Table 1. Wavenumber $\left(\mathrm{cm}^{-1}\right)$ values for the electron-phonon coupling by the Bose-Einstein equation.

\begin{tabular}{|c|c|c|c|c|}
\hline probe & \multicolumn{2}{|c|}{ Sample } & w $\left(\mathrm{cm}^{-1}\right)$ & $\chi^{2}$ \\
\hline \multirow{3}{*}{$1 \mathrm{Py}(3) 1 \mathrm{Py}$} & \multirow{3}{*}{ unstretched } & first heating & $2795 \pm 61$ & 0.00331 \\
\cline { 3 - 5 } & & cooling & $2973 \pm 108$ & 0.00876 \\
\cline { 3 - 5 } & \multirow{3}{*}{ stretched } & first heating & $3610 \pm 144$ & 0.00249 \\
\cline { 3 - 5 } & & cooling & $3028 \pm 209$ & 0.00136 \\
\cline { 3 - 5 } & & second heating & $3003 \pm 140$ & 0.00086 \\
\hline Pyrene [12,13] & \multicolumn{2}{|c|}{ unstretched-first heating } & $2810 \pm 35$ and $1437 \pm 61$ & \\
\hline
\end{tabular}

$\chi^{2}$ correlation coefficient. 
The macroscopic stretching of a host matrix may induce two types of effects upon the guest molecules: partial orientation of the guest along the drawing direction and its displaced toward a more restraint environment [5,11]. In addition, the macroscopic stretching of a crystalline polymer film induces some morphological changes including orientation of the crystallites along the drawing direction, increasing the crystallinity degree and reducing the freevolume in the amorphous phase $[3,59,60]$. Thus, a higher electron-phonon coupling wavenumber for a guest dissolved in a stretched compared with an unstretched host is not surprising. This fact may reflect a stronger host/guest coupling produced by the lower available free-volume.

Polyethylene has numerous vibrational modes, some of them coupled by Fermi resonance, producing vibrational bands with complex profiles in infrared and Raman spectra [61-63]. Several types of segmental couplings produced by the trans-sequences of the methylene units can split the normal vibrational modes, introducing additional complexity to the vibrational spectrum of polyethylene in the solid state. In particular, there are several vibrational bands belonging to the $A_{g}$ and $B_{l g}$ symmetry species, in the spectral range $2950-2800 \mathrm{~cm}^{-1}$, including the symmetrical and antisymmetrical $\mathrm{CH}_{2}$ stretching modes. Overlapped with these fundamental modes, there are overtones and combinations of the fundamental bending modes (1440 and $1416 \mathrm{~cm}^{-1}$ ) whose intensities are enhanced by Fermiresonance [61-63]. The calculated electron-phonon wavenumbers are in the range $2800-3000 \mathrm{~cm}^{-1}$ up to 250 $\mathrm{K}$, which are almost coincident with the in-phase $\mathrm{CH}_{2}$ stretching modes we have found previously for pyrene [14] (Table 1).

It is noteworthy that the vibrational modes of the higher energy vibronic band of the fluorescence spectrum of pyrene belong to the same irreducible representation $\left(\mathrm{a}_{\mathrm{g}}\right)$ of the coupled modes of the polymer host $\left(A_{g}\right)$. Thus, we might suggest that the $\mathrm{C}-\mathrm{H}$ stretching modes of the matrix take an important role in the vibrational energy distribution that gives origin to the emission bands at $367 \mathrm{~nm}$ and $375 \mathrm{~nm}$, at least in the temperature ranges $173-280 \mathrm{~K}$ (unstretched) or $173-300 \mathrm{~K}$ (stretched), although we can not define a detailed mechanism [64-68].

\subsection{Temperature Dependence of the Monomer Emission}

In order to analyze the temperature dependence of the two envelopes of the emission bands, for the monomer Table 2. Relasation temperatures and apparent activation energies, $\mathrm{E}_{\mathrm{a}}$ for $1 \mathrm{Py}(3) 1 \mathrm{Py}$ in LDPE.

\begin{tabular}{|c|c|c|c|c|c|}
\hline & \multicolumn{2}{|c|}{ unstretched LDPE } & \multicolumn{3}{|c|}{ Stretched LDPE } \\
\hline & first heating & cooling & first heating & cooling & second heating \\
\hline $\mathrm{T}_{p} / \mathrm{K}$ & 268 & 284 & * & 268 & * \\
\hline $\mathrm{E}_{\mathrm{a}} / \mathrm{kJ} \mathrm{mol}^{-1}$ & 11 & 13 & 10 & 6.5 & 10 \\
\hline $\mathrm{T}_{\alpha} / \mathrm{K}$ & 295 & 300 & 320 & 295 & 300 \\
\hline $\mathrm{E}_{\mathrm{s}} / \mathrm{kJ} \mathrm{\textrm {mol } ^ { - 1 }}$ & 47 & 54 & 77 & 52 & 51 \\
\hline $\mathrm{T}_{\mathrm{m}} / \mathrm{K}$ & 378 & 366 & 366 & 372 & 377 \\
\hline $\mathrm{E}_{\mathrm{s}} / \mathrm{kJ} \mathrm{\textrm {mol } ^ { - 1 }}$ & 17 & 22 & $* *$ & 14 & $* *$ \\
\hline
\end{tabular}

*out of the temperature range; ** non-Anhenius process. centered at $390 \mathrm{~nm}$ and that other for the excimer at $480 \mathrm{~nm}$, we initially consider that the spectrum is only due to a single fluorescent specie, the monomer. Although we do not develop a complete relationship for the dependence of the excimer formation on the fluorescence intensity of the monomer, the excimer emission is effectively competitive processes that decrease the fluorescence intensity of the monomer. Furthermore, there are several approaches aready developed to describe the relationship between the temperature and the fluorescence intensity (or decay rates) of probes in polymer matrices, although a unique model has not studies were developed as attempt to describe the dependence of the photophysical on the viscoelastic properties of the medium and again a straightforward relationship could not be obtained [16-20,22,29,30].

According to our approach, we first assumed that the excimer emission is absent, which is virtually only for lowest temperatures. Under this assumption we represented the plots of the dependence of the normalized and integrated fluorescence intensity versus the temperature by an Arrhenius-like expression (eq. 2) as shown in Fig. (3):

$$
\ln \left[\left(\frac{I_{0}}{I}\right)-1\right]=A+\frac{E_{a}}{R T}
$$

This assumption and photophysical model consider that the plot should be linear if all bimolecular energy transfer processes (including the excimer formation) were absent and the sum of all unimolecular rate constants was related to a

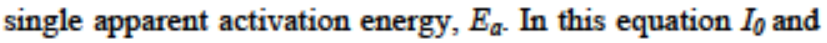
$I$ are the integrated fluorescence intensities of the isolated pyrenyl moiety at the lowest temperature and at $\mathrm{T}$, respectively $[10,11,13-15]$. As showed in Fig. (1)) we consider that it is virtually true only for temperatures below $280 \mathrm{~K}$.

Our data showed that the Arrhenius plots may be divided into three temperature ranges: $173-290 \mathrm{~K}, 290-380 \mathrm{~K}$ and $380-423 \mathrm{~K}$ (Fig. (3)). The data for the first two temperature ranges were fitted by the Arrhenius-like expression (equation 2) with one apparent activation energy value for each one. Nevertheless, this type of expression could not fit those data obtained in the higher temperature range, whose onset transition temperature was coincident with the LDPE melting process $(370 \pm 5 \mathrm{~K})$ independent of sample stretching (Table 2). Another linear segment was obtained for the $290-380 \mathrm{~K}$ yet been established even for solutions. In addition several 
range, with the onset temperatures at $290 \mathrm{~K}$ and $310 \mathrm{~K}$, for the sum of all thermal cycles and the first heating of the stretched sample, respectively.

The apparent activation energy value for the first heating of the stretched sample was also larger, ca. $77 \mathrm{~kJ} \mathrm{~mol}^{-1}$, than the values for the others cycles, ca. $50 \pm 4 \mathrm{~kJ} \mathrm{~mol}^{-1}$. Finally, the onset temperatures of ca. $250-260 \mathrm{~K}$ for the lower temperature range $(173-270 \mathrm{~K})$ and the corresponding apparent activation energies, ca. $10 \pm 4 \mathrm{~kJ} \mathrm{~mol}^{-1}$, were very similar for both stretched and unstretched samples.

The non-Arrhenius behavior for the temperature dependence of the $1 \mathrm{Py}(3) 1 \mathrm{Py}$ monomer fluorescence at $\mathrm{T}>$ $\mathrm{T}_{\mathrm{m}}$ probably resulted from several synergic effects including the simultaneous presence of the unimolecular (isolated pyrenyl group) and bimolecular (ground-state dimer) photophysical pathways involved with the deactivation processes and changes of the viscoelastic properties of the polymer matrix as it became a viscous media.

\subsection{Excimer Fluorescence: Kinetic Model}

The 1Py(3)1Py intramolecular excimer emission exhibited an onset temperature at ca. $280 \mathrm{~K}$ (unstretched) and $310 \mathrm{~K}$ (stretched), which was coincident with the reduction of the emission at $367 \mathrm{~nm}$. The maximum intensity of the excimer emission occurred at $\mathrm{T} \cong 350-360 \mathrm{~K}$ for both unstretched (Fig. (2a, b)) and stretched samples (Fig. (2c-e)).

There are several types of kinetic approaches for the description of the excimer formation in different types of systems $[27,28,67]$. For an attempt to describe our data for the temperature dependence of the excimer emission obtained using steady-state fluorescence spectroscopy we considered the simple kinetic model described in the Scheme 1. This Scheme assumes a complete absence of pre-formed intermolecular dimers in the electronic ground state $[58,67]$ and was considered reasonable because of the low concentration of the probe in the samples and because excimer emission at low temperatures was undetectable. We also considered that the appearance of an isoemissive point in a closed system under steady-state excitation with two emitting species (monomer and excimer) provides evidence that the concentrations of both species were linearly correlated $[16,17,67,68]$.
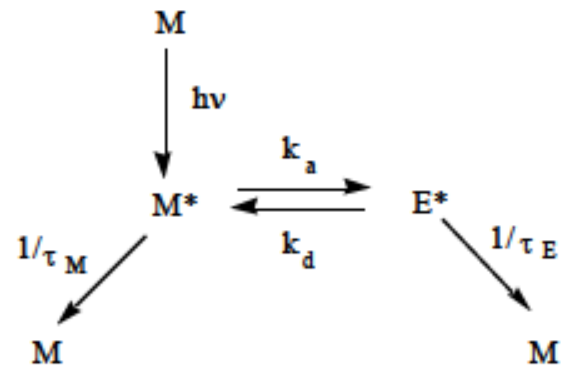

where: $\mathrm{k}_{\mathrm{a}}$ and $\mathrm{k}_{\mathrm{d}}$ are the rate constants for excimer formation and dissociation, respectively; and $\mathrm{k}_{\mathrm{FM}}=1 / \tau_{\mathrm{M}}$ and $\mathrm{k}_{\mathrm{FE}}=1 / \tau_{\mathrm{E}}$ are the lifetimes for monomer and excimer fluorescence emissions, respectively.
Considering the kinetic processes described in Scheme 1, a general expression for the $I_{E} / I_{M}$ ratio was obtained [68]:

$$
\ln \left[\left(\frac{I_{0}}{I}\right)-1\right]=A+\frac{E_{a}}{R T}
$$

where: $\mathrm{k}_{\mathrm{M}}$ and $\mathrm{k}_{\mathrm{E}}$ are the rate constants for the monomer and excimer deactivations that include both the radiative $\left(\mathrm{k}_{\mathrm{FM}}\right.$ and $\mathrm{k}_{\mathrm{FE}}$ ) and the non-radiative deactivation processes, respectively; $\Phi_{\mathrm{FM}}$ and $\Phi_{\mathrm{FE}}$ are the quantum yields for the monomer and excimer emissions, respectively, which are considered temperature independent; and $\mathrm{k}_{\mathrm{a}}$ and $\mathrm{k}_{\mathrm{d}}$ are the rate constants for excimer formation and dissociation, respectively $[67,68]$.

Two types of approximation may be considered for equation 3 [67]. At the low temperature limit, we have $k_{d} \ll$ $\mathrm{k}_{\mathrm{E}}$, and, then:

$$
\frac{I_{E}}{I_{M}} \cong\left(\frac{k_{F E}}{k_{F M}}\right)\left[\frac{k_{o}[M]}{k_{E}}\right]=\frac{\Phi_{F E}}{\Phi_{F M}} \tau_{M} k_{a}[M]
$$

showing that the ratio $\mathrm{I}_{\mathrm{E}} / \mathrm{I}_{\mathrm{M}}$ increases as the temperature increase; the Arrhenius representation is linear and the slope is proportional to the activation energy for intramolecular excimer formation:

$$
E_{\alpha}=\left[\frac{d \ln \left(\frac{I_{g}}{I_{M}}\right)}{d T}\right]
$$

At the high temperature limit, the rate constant $k_{d} \gg k_{E}$; thus, the $I_{E} / I_{M}$ ratio decreases with temperature, and the Arrhenius plot of the rate constants versus $1 / T$ renders the entropy and enthalpy for the excimer formation. Between the high and the low temperature limits, the Arrhenius plot produces a flattened maximum [67].

The Arrhenius plots for the experimental data (equation 5) presented in Fig. (5) consider the very simple kinetic model (Scheme 1) and, may be divided into three sets of temperature ranges: i) very low temperatures (up to $280 \mathrm{~K}$ ), where the excimer emission was completely absent; ii) the intermediate temperature range, where the curve profile was linear. The system might be considered at the low temperature limit $(280 \mathrm{~K}<\mathrm{T}<370 \mathrm{~K})$. Assuming the same kinetic model, the excimer formation process is represented by equation 4 ; iii) for $\mathrm{T}>370 \mathrm{~K}$, a flattened maximum was observed, suggesting the possible contribution of ground state dimers produced by the free rotation of the pyrenyl moieties $[58,67]$. 


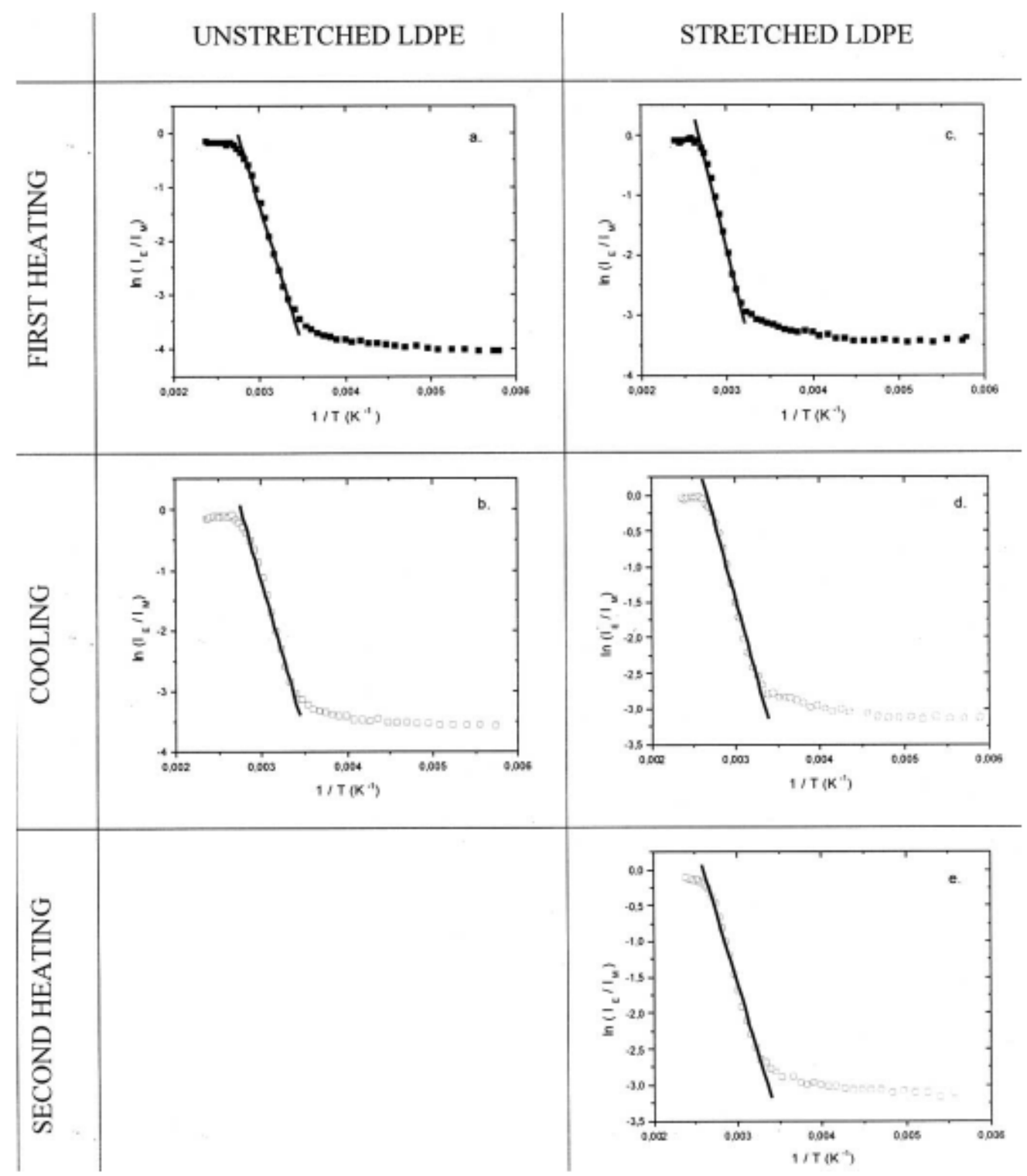

Fig. (5). Arrhenius plot for the excimer/monomer emission, $I_{E} / I_{M}$ versus $1 / T$, for $1 P y(3) 1 P y$ in low density polyethylene in unstretched (a. heating and b. cooling cycles) and stretched (c. first heating, d. cooling and e. second heating cycles) at several temperatures.

The analytical solution for the linear segment of the Arrhenius plot, $\ln \left(\mathrm{I}_{\mathrm{E}} / \mathrm{I}_{\mathrm{M}}\right)$ versus $\mathrm{T}^{-1}$, at the low temperature range $\left(\mathrm{k}_{\mathrm{d}} \ll \mathrm{k}_{\mathrm{E}}\right)$ (equation 5 , Fig. (5)) resulted in apparent activation energies for excimer formation dependent on the polymer stretching as: $\mathrm{E}_{\mathrm{a}} \approx 43 \mathrm{~kJ} \mathrm{~mol}^{-1}$ for both the heating and cooling cycles of $1 \mathrm{Py}(3) 1 \mathrm{Py}$ in an unstretched sample; $\mathrm{E}_{\mathrm{a}} \approx 50 \mathrm{~kJ} \mathrm{~mol}^{-1}$ for the first heating cycle and $\mathrm{E}_{\mathrm{a}} \approx 35 \mathrm{~kJ}$ $\mathrm{mol}^{-1}$ for both the cooling and the second heating cycles of $1 \mathrm{Py}(3) 1 \mathrm{Py}$ in a stretched sample. The higher $\mathrm{E}_{\mathrm{a}}$ value for the stretched film constitutes additional evidence that the probe was confined to a lower free-volume microenvironment. These values are substantially higher than the activation energy for excimer formation of $1 \mathrm{Py}(3) 1 \mathrm{Py}$ in liquid solvents (n-heptane), obtained from Arrhenius plots of the decay rate constants, ca. $18-20 \mathrm{~kJ} \mathrm{~mol}^{-1}$, revealing the presence of steric hindrances for excimer formation in the solid matrices [27].

The efficiency of the intramolecular excimer emission is suggested to be lower for probes dissolved in polymer matrices compared to non-viscous solvents, since the adequate conformation of the moieties is controlled by the polymer free-volume in the vicinity of the probe [16-20]. On the other hand, the guests in host matrices are distributed in polymer sites with a distribution of size and shape that are more rigid or more flexible, depending on the temperature. For example, at lower temperatures, the segments of the 
chains forming the walls of these cavities are immobilized, inhibiting the intramolecular rotation of the probe and, consequently, the excimer conformation can not be achieved. At higher temperatures, some of cavities become mobile enough to allow conformational changes for the $1 \mathrm{Py}(3) 1 \mathrm{Py}$ molecules and a dynamic excimer can be formed [26]. In agreement with this proposal, the temperature dependence of the excimer fluorescence (Fig. (2) and (5)) demonstrated that the mechanism involved in the excimer formation was strongly dependent on the free-volume necessary for the rotation of the pyrenyl moieties. Consequently, we propose that the slope changes observed in the Arrhenius plot must be related to the polymer relaxation processes that generate an additional free-volume adequate for the intramolecular excimer formation. It is also noteworthy that the temperatures for these processes were coincident with those observed, for different reasons, for the changes of the relative intensities of the bands at $367 \mathrm{~nm}$ and $390 \mathrm{~nm}$.

\subsection{Polyethylene Relaxation Processes}

Polyethylene is a polymer that exhibits several types of relaxation processes, all of them subject to controversial assignments $[10,11,13-15,31-56]$. As a semi-crystalline polymer, the highest temperature transition corresponds to melting of the crystalline phase, which was determined by $\mathrm{dsc}$ to be $\mathrm{T} \approx 380 \mathrm{~K}$ for the present sample. Thus, any guest dissolved in melted polyethylene behaves as in a viscous fluid medium and, consequently, the conformational changes might be defined by the stability of the rotational conformer. The fluorescence spectra shown in Fig. 1 revealed that both isolated pyrenyl and excimer emissions occurred at temperatures above the melting process. To explain the experimental results, we suggested a very simple kinetic scheme and the apparent activation energy for excimer formation was calculated as being higher for stretched matrix $[66,67]$.

Below the melting temperature, the polymer crystallization process takes place, excluding the guest molecules from the crystalline phase of the host. The probable locations of the guests are in the amorphous phase and at the interface between the crystalline and amorphous phases [5,6,10,11,13-15]. In an attempt to explain our experimental results, that excimer formation is inhibited at low temperatures but appears at $T>T_{\beta}$, we suggest that, between the melting and the low temperature transitions, the cavities, where the guests are located in the amorphous region of the polymer host retain a certain mobility, resulting from the mobility of short segments of the macromolecular chains. If the dimensions of these macromolecular segments are similar to those of the guest molecules, some probe molecules might be confined in larger cavities and might undergo intramolecular rotations achieving adequate conformations of the pyrenyl moieties to form excimer species. Thus, in this temperature range, excimer formation is a thermally activated process related to the free-volume in the polymer matrix. Finally, in the lower temperature range ( $170 \mathrm{~K}<\mathrm{T}<250 \mathrm{~K})$, the polymer segments are frozen, even in the amorphous region; the rigidity of the cavity imposes steric hindrances on the conformational changes of the guest and no excimer emission is observed.
There are three temperature ranges $(423-380 \mathrm{~K}, 380-270$ $\mathrm{K}$ and $270-173 \mathrm{~K}$ ) for LDPE where photophysical changes of the $1 \mathrm{Py}(3) 1 \mathrm{Py}$ were observed. The higher temperature range, $423-380 \mathrm{~K}$, is characterized by: i) an equilibrium involving excimer and isolated pyrenyl moiety emission; ii) absence of electron-phonon coupling; and, iii) isolated pyrenyl moiety emission exhibiting a non-Arrhenius behavior. The melting temperatures determined by the excimer and monomer fluorescence emissions are very similar and coincident with the dsc measurements (Table 2). The values were virtually independent of the micromorphology changes of the samples produced by stretching, revealing that the samples could relax at temperatures below the melting process.

The second change of the $1 \mathrm{Py}(3) 1 \mathrm{Py}$ photophysical properties is observed in the temperature range $295-370 \mathrm{~K}$, with the onset temperature depending on the stretching state of the samples. The lower onset temperature is related to the onset temperature for the decrease of the fluorescence intensity of the isolated pyrenyl moiety and it is also coincident with the onset temperature for excimer emission. Further, this transition temperature is $\approx 20 \mathrm{~K}$ higher for stretched than for unstretched samples. The onset temperature was lower than that determined using smaller fluorescent probes, such as anthracene $(T \approx 340 \mathrm{~K}$ ) $[10,11,13]$ or pyrene $(T \approx 330-340 \mathrm{~K})[14,15]$, in agreement with other studies indicating that larger molecules can sense relaxation processes involving longer segments or that they plastify more efficiently the microenvironment in which they are located [21].

Moreover, it has been reported that polyethylene exhibits an $\alpha$-relaxation in the temperature range of $300-340 \mathrm{~K}$ that involves motions of chain units located in the crystalline and at the interfacial regions between the amorphous and the crystalline phases of the polymer matrix [34]. Since the sorption processes of $1 \mathrm{Py}(3) 1 \mathrm{Py}$ in a polyethylene matrix limits the access of the guests to the amorphous phase and the interface and that, subsequent to crystallization, they are excluded from the crystalline phase, the fluorescent probes can only sense the amorphous phase or the crystallineamorphous interface $[10,11,13-15]$. Thus, the $\alpha$-relaxation processes sensed by fluorescent probes can only be related to these two types of domains.

In addition, the macroscopic orientation of the polymer/guest system induced by stretching has three simultaneous effects: i) the partial orientation of the long guest axis along the stretching direction; ii) a translocation of such guests to the interfacial regions $[10,11]$; and iii) modification of the ratio of trans to gauche conformations of the polymer chain as an explanation for the difference observed in the frequency coupling for stretched and unstretched samples, although we do not have any additional experimental evidence to confirm this point.

Thus, the higher temperature relaxation processes and the higher activation energy values obtained for the photophysical processes of both the excimer and monomer species in stretched films demonstrate that the guests are preferentially probing more rigid domains (amorphous and interface regions) than in the unstretched samples. This conclusion is in agreement with previous reports referring to the 
displacement of the molecules to a more restraint domains in stretched matrices [11].

In the lower temperature range $(173-270 \mathrm{~K})$ where no excimer emission is observed, the electron-phonon coupling model seems to be adequate to describe the vibrational couplings of the pyrenyl-group with the polyethylene matrix normal modes and the monomer fluorescence intensity is well represented by an Arrhenius plot. Lower apparent activation energy values $\left(10-13 \mathrm{~kJ} \mathrm{~mol}^{-1}\right)$ are obtained and the onset temperature is virtually independent of the matrix orientation at $\mathrm{T}=270 \mathrm{~K}$. Although the temperature dependence for the band at $367 \mathrm{~nm}$ and the envelope at $390 \mathrm{~nm}$ are virtually independent of the macroscopic stretching of the sample, in agreement with previous reports $[10,11,13]$, the wavenumber calculated from the electron-phonon coupling model is higher for stretched sample. We attribute the onset of this lower relaxation temperature, ca. $270 \mathrm{~K}$, to the disturbance of the guest microenvironment produced by the polyethylene $\beta$ relaxation that was reported to occur in the range $240-270 \mathrm{~K}$ $[10,11,13,34]$, involving the amorphous region of the polymer matrix.

These results are in complete agreement with the polymer relaxation temperatures determined by other techniques [31-56] and with our previous works using other guests (pyrene $[14,15]$ and anthracene $[10,11,13,25])$.

\section{CONCLUSIONS}

The photophysical properties of $1 \mathrm{Py}(3) 1 \mathrm{Py}$ as a guest in a LDPE host were studied. The fluorescence spectrum of this molecule was dependent on the temperature and was strongly related to the polymer relaxation processes. Similarly to pyrene, the $1 \mathrm{Py}(3) 1 \mathrm{Py}$ fluorescence spectrum exhibited a vibronic band at higher energy than the $0-0$ emission, whose temperature dependence reflects the coupling between excited pyrene and the vibrating environment. The wavenumbers of the coupled phonons for both $1 \mathrm{Py}(3) 1 \mathrm{Py}$ and pyrene were calculated by fitting the fluorescence intensity to the Bose-Einstein factor. The calculated phonons were similar to the $\mathrm{CH}_{2}$ stretching vibrations of polyethylene. The coupling wavenumber was higher for the stretched guest/host system revealing a stronger coupling in a more rigid environment. The effect of stretching on the photophysical properties was removed at temperatures lower than that of polymer melting and, probably, was occurring as a consequence of the LDPE $\alpha$-relaxation process. Although the electron-phonon coupling model is able to simulate the temperature dependence of the emission at lower temperatures, it failed at higheratures.

A complete lack of excimer emission occurred at low temperatures and was explained by the absence of groundstate dimers and the impossibility to achieve the excimer conformation in the solid state matrix. Arrhenius temperature dependence for the $I_{E} / I_{M}$ ratio was obtained only for the intermediate temperature range, suggesting that a dynamic mechanism for excimer formation with rotation of the pyrenyl moieties is involved. At temperatures higher than polymer melting a flattened maximum of the Arrhenius plot was observed, suggesting that the high temperature limit for excimer formation was being reached. The activation energy for 1 Py(3)1Py excimer formation in unstretched LDPE was $43 \mathrm{~kJ} \mathrm{~mol}^{-1}$, lower than for oriented samples $\left(\approx 50 \mathrm{~kJ} \mathrm{~mol}^{-1}\right)$. The dynamics of excimer formation was also controlled by the polymer relaxation processes and was strongly dependent on the size of the longer segments, similar to that involved in the polyethylene $\alpha$-relaxation process $(T \approx 320-340 \mathrm{~K}$ ) [34]. This indicated that the probe could not undergo the conformational changes required for excimer formation, and that this change was controlled by the free-volume available in the neighborhood of the chromophore and, ultimately, by the polymer relaxation processes.

\section{ACKNOWLEDGEMENTS}

J. B. thanks Brite EuRam/EU (BE97-4472) and to CICYT (MAT2000-0391-P4-02) for financial support. T. D. Z. A. thanks FAPESP and CNPq (Brazil) for financial support and a fellowship. S. B. Y. thanks FAPESP (Brazil) for a fellowship. The authors thank Prof. Carol Collins for useful discussions.

\section{REFERENCES}

[1] Renfew, A. and Morgan, P., Polyethylene: The Technology and Uses of Polyethylene Polymers, Wiley-Interscience, New York, 1957.

[2] Mark, H. F.; Bibales, N. M.; Overberger, C. G.; Menges, G. (Editors), Encyclopedia of Polymer Science and Engineering, Wiley-Interscience, New York, $2^{\text {nd }}$ Edition, 1986.

[3] Peterlin, A. J. Polym. Sci., 1969, 7, 1151.

[4] Wignall, G. D.; Londomo, J. D.; Lin, J. S.; Adamo, R. G.; and Mandelkern, L. Macromolecules, 1995, 28, 3156.

[5] Michl, J., Thulstrup, E. W., Spectroscopy with polarized light: solute alignment by photoselection in liquid crystals, polymers, and membranes. VCH Publishers Inc., New York, $2^{\text {nd }}$ Edition, p.359, 1995.

[6] Phillips, P. J. Chem. Rev., 1990, 90, 425.

[7] He, Z; Hammond, G. S., Weiss, R. G. Macromolecules, $1992,25,1568$.

[8] Cui, C.; Weiss, R. G. J. Am. Chem. Soc., 1993, 113, 9820.

[9] Serna, C.; Abbe, J. Ch.; Dupatre, G. Phys. Stat. Solid. A, $1989,115,389$.

[10] Talhavini, M.; Atvars, T. D. Z; Cui, C., Weiss, R. G. Polymer, 1996, 37, 4365.

[11] Talhavini, M.; Atvars, T. D. Z.; Schurr, O., Weiss, R. G., Polymer, 1998, 39, 3221.

[12] Winnik, M. A. (editor), Photophysical and Photochemical Tools in Polymer Science: conformation, dynamic and morphology, NATO ASI Series, Vol 182, Riedel, Dordrech, The Netherlands, 1986. 
[13] Martins-Franchetti, S. M., Atvars, T. D. Z. Eur. Polymer J., 1995, 31, 467.

[14] Vigil, M. R.; Bravo, J.; Atvars, T. D. Z.; Baselga, J. Macromolecules, 1997, 30, 4871.

[15] Vigil, M. R.; Bravo, J.; Atvars, T. D. Z.; Baselga, J. J. NonCrystalline Solids, 1998, 235-237, 554.

[16] Bokobza, L.; Pham-Van-Cang, C.; Gioradano, C.; Monnerie, L.; Vandendriessche, J.; De Schryver, F. C.; Kontos, E. G. Polymer, 1987, 28, 1876.

[17] Jing, D. P.; Bokobza, L.; Monnerie, L.; Collart, P.; De Schryver, F. C. Polymer, 1990, 31, 110

[18] Klopffer, M-H.; Bokobza, L.; Monnerie, L. Macromol. Symp., 1997, 119, 119.

[19] Lauprêtre, F.; Bokobza, L.; Monnerie, L. Polymer, 1993, $34,468$.

[20] Lauprêtre, F.; Bokobza, L.; Monnerie, L. Macomolecules, 1998, 31, 8291 .

[21] Christoff, M.; Atvars, T. D. Z. Macromolecules, 1999, 32, 6093.

[22] Ye, J. Y.; Hattori, T.; Nakatsuka, H. Phys. Rev. B, 1997, $56,5286$.

[23] Ramesh, V.; Weiss, R. G. Macromolecules, 1986, 19, 1486.

[24] Cui, C.; Naciri, J.; He, Z.; Jenkins, R. M.; Lu, L.; Ramesh, V.; Hammond, G. S.; Weiss, R. G. Química Nova, 1993, 16,578 .

[25] Yamaki, S. B.; Weiss, R. G.; Atvars, T. D. Z. submitted 2002

[26] Zimerman, O. E.; Weiss, R. G. J. Phys. Chem. A, 1998, 102, 5364 .

[27] a. Reynders, P.; Kühnle, W.; Zachariasse, K. A. J. Phys. Chem., 1990, 94, 4073; b. Zachariasse, K. A.; Kühnle, W.; Leinhos, U.; Reynders, P.; Striker, G. J. Phys. Chem., 1991, 95,5476

[28] Siemiarzuk, A.; Ware, W. R. Chem. Phys. Lett., 1987, 140, 277.

[29] Guillet, J. Polymer Photophysics and Photochemistry, Cambridge University Press, Cambridge, 1985

[30] Bokobza, L. Progr. Polym. Sci., 1990, 15, 337.

[31] Mandelkern, L., Physical Properties of Polymers, American Chemical Society, Washington, D.C., chap. 4, 1993

[32] Mandelkern, L. Acc. Chem. Res., 1990, 23, 380.

[33] Berstein, V. A.; Egorov, V. M. Differential Scanning Calorimetry of Polymers; Horwood:Hemmel, Hempstead, Great Britain, p. 65, 1994.

[34] Ohta, Y.; Yasuda, H. J. Polym. Sci. Part B: Polym. Phys., 1994, 32, 2241.

[35] Alberola, N.; Cavaille, J.Y.; Perez, J. J. Polym. Sci. Polym. Phys., 1990, 28, 569.
[36] Alberola, N.; Cavaille, J.Y.; Perez, J. Eur. Polym. J., 1992, 28,935 .

[37] Anada, Y.; Kakizaki, M.; Hideshima, T. Jpn. J. Appl. Phys., 1984, 23, 247.

[38] Anada, Y.; Kakizaki, M.; Hideshima, T. Jpn. J. Appl. Phys., 1984, 23, 497.

[39] Bensason, S.; Minick, J.; Moet, A.; Chum, S.; Hjltner, A.; Baer, E. J. Polym. Sci. Polym. Phys. 1996, 34, 1301.

[40] Atvars, T.D.Z.; Sabadini E.; Martins-Franchetti, S.M. Eur. Polym. J., 1993, 29, 1259.

[41] Boyer, R.F. J. Polym. Sci. Polym. Sym., 1975, 50, 189.

[42] Compañ, V.; Diaz-Calleja, R.; Ribes, A.; Andrio, A.; Lopez, M.L.; Riande E. J. Appl. Polym. Sci., 1996, 60, 767.

[43] Fukui, S.; Hideshima, T. Jpn. J. Appl. Phys., 1977, 16, 497.

[44] Fukui, S.; Hideshima, Jpn. J. Appl. Phys., 1977, 16, 159.

[45] Gradin, P.L.; Howgate, P.G.; Seldén, R.; Brown, R. A. in Allen, G.; Benvington, J. C. (editors), Comprehensive Polymer Science, Pergamon Press, Oxford, 1996, Vol. 2, Chap. 16.

[46] Hendra, P.J.; Passingham, C.; Jones, S.A. Eur. Polym. J., 1991, 27, 127 .

[47] Illers, K.H.; Kolloid Z. Z. Polym., 1969, 231, 622.

[48] Jin, Y.; Boyd, R.H. J. Chem. Phys., 1998, 108, 9912.

[49] Kakizaki, M.; Kakudate, T.; Hideshima, T. J. Polym. Sci. Part B: Polym. Phys., 1985, 23, 809.

[50] Kakudate, T.; Kakizaki, M.; Hideshima, T. J. Polym. Sci. Part B: Polym. Phys., 1985, 23, 787.

[51] Khanna Y.P.; Turi E.A.; Taylor T.J.; Vickroy V.V.; Abbott R.F. Macromolecules, 1985, 18, 1302.

[52] Martins-Franchetti, S.M.; Atvars, T.D.Z. J. Appl. Polym. Sci., 1993, 50, 1591.

[53] Popli, R.; Glotin, M.; Mandelkern, L.; Benson, R. S. J. Polym. Sci. Part B: Polym. Phys., 1984, 22, 407.

[54] Uedono, A.; Suzuki, R.; Ohdaira, T.; Uozumi, T.; Ban, M.; Kyoto, M.; Tanigawa, S.; Mikado, T. J. Polym. Sci. Polym. Phys., 1998, 36, 2597.

[55] Woo, L.; Ling, M.T.K.; Westphal, S.P. Thermochim. Acta, 1996, 272, 171 .

[56] Yamada, Y.; Kakizaki, M.; Hideshima, T. Jpn. J. Appl. Phys. 1, 1982, 21, 352.

[57] Serrano, B.; Levenfeld, B.; Bravo, J.; Baselga, J. Polym. Eng. Sci., 1996, 36, 175.

[58] Birks, J. B. Photophysics of Aromatic Molecules, Wiley Interscience, London, 1970.

[59] Hobeika, S.; Men, Y.; Strobl, G. Macromolecules, 2000, 33, 1827. 
[60] Baird, D. G.; Collias, D. I. Polymer Processing: Principle and Design, John Wiley \& Sons, New York, 1998, p. 126.

[61] Snyder, R. G.; Scherer, J. R. J. Chem. Phys., 1979, 71, 3221.

[62] Massetti, G.; Abbate, S.; Gussoni, M.; Zerbi, G. J. Chem. Phys., 1980, 73, 4671.

[63] Gerrard, D. L.; Maddams, W. F. Appl. Spectr. Rev., 1986, 22,251 .

[64] Robinson, G. W.; Frosch, R. P. J. Chem. Phys., 1962, 37, 1962.

[65] Robinson, G. W.; Frosch, R. P. J. Chem. Phys., 1963, 38, 1187.

[66] Lin, S. H.; Bersohn, R. J. Chem. Phys., 1968, 37, 2732.

[67] Pierola, I. F.; Horta, A. Rev. Iberoam. Pol., 1992, 1, 49.

[68] Stevens, B.; Ban, M. I. Trans. Faraday Soc., 1964, 60, 1515 . 